\title{
Design and testing of AR coatings for MEGARA optics
}

\author{
R. Ortiz ${ }^{\text {a }}$, E. Carrasco ${ }^{\text {a }}$, G. Páez ${ }^{\text {b }}$ O. Pompa ${ }^{\text {b }}$, E. Sánchez-Blanco ${ }^{\text {c }}$, A. Gil de Paz ${ }^{\text {d, J. Gallego }}{ }^{\text {d, J. }}$ \\ Iglesias-Páramo $^{\mathrm{e}}$ \\ ${ }^{a}$ Instituto Nacional de Astrofísica Óptica y Electrónica, Luis Enrique Erro 1, Tonantzintla, Puebla, \\ Mexico; ${ }^{b}$ Centro de Investigaciones en Óptica, León, Guanajuato, Mexico; ${ }^{c}$ Fractal SNLE, Spain; \\ ${ }^{\mathrm{d}}$ Universidad Complutense de Madrid, Spain; ${ }^{\mathrm{e}}$ Instituto de Astrofísica de Andalucía, Spain.
}

\begin{abstract}
We present the antireflection coatings of the optical elements of MEGARA, the new integral field and multi-object spectrograph for the Gran Telescopio Canarias. We describe the methodology for optimizing the solutions. We also present the results of the final deposited coatings. The main optics require broadband coatings in the range from $370 \mathrm{~nm}$ to $980 \mathrm{~nm}$ for different materials with a mean $\mathrm{R}<1.3 \%$ at specific angles of incidence in each surface. For each material a specific arrangement of thicknesses of the same eight layers were produced and tested. For the spectrograph pupil elements four layer coatings were designed and produced $\mathrm{R}<0.3 \%$. The design of main optics and pupil elements coatings have been shared between INAOE and CIO. The coating depositions have been performed at CIO in the Integrity 39 Denton Vacuum Deposition System. The main optics final coatings fulfill MEGARA requirements.
\end{abstract}

Keywords: antireflection coatings, optical design, thin films, optical testing, broadband coatings, MEGARA, GTC

\section{INTRODUCTION}

MEGARA ${ }^{1,2,3}$ (Multi-Espectrógrafo en GTC de Alta Resolución para Astronomía) is an optical Integral-Field Unit (IFU) and Multi-Object Spectrograph (MOS) designed for the GTC 10.4m telescope, in operation in La Palma (Spain). It has been developed under a contract with GRANTECAN. The MEGARA Consortium is led by Universidad Complutense de Madrid and has as co-partners the Instituto Nacional de Astrofísica, Óptica y Electrónica (INAOE. Mexico), the Instituto de Astrofísica de Andalucía (IAA-CSIC, Spain) and the Universidad Politécnica de Madrid (UPM, Spain).

The instrument has an IFUs plus a MOS mode: a large compact bundle covering $12.5 \operatorname{arcsec}$ x $11.3 \operatorname{arcsec}$ on sky with $100 \mu \mathrm{m}$ fiber-core; a fiber MOS positioner that allows to place up to 100 mini-bundles, 7 fibers each, with $100 \mu \mathrm{m}$ fibercore, within a 3.5 arcmin x 3.5 arcmin field of view, around the IFU. The fibers, organized in bundles, end in the pseudoslit plate located at the entrance of MEGARA spectrograph. The collimator and camera optics and optomechanics are finished and delivered to UCM where the instrument integration is in progress.

In this work we present the results of the depositions of the AR coatings of the main optics elements. Throughput requirements are essential in any optical system, especially for astronomy. These are the considerations used for the throughput budget as we have divided the contributors to the GTC + MEGARA Throughput budget in the following parts:

- GTC optical mirror (reflectivity as in GTC documentation).

- MEGARA Folded-Cassegrain subsystems, which include all MEGARA subsystems from Field lens to the fiber exit at the spectrograph entrance.

- MEGARA spectrograph common optical path subsystems, which include the collimator plus camera optics spectrograph and the detector.

- $\quad$ MEGARA gratings, which provides the values for all Low-Resolution (LR), Medium-Resolution (MR) and High-Resolution (HR) gratings.

AR coatings are included in the MEGARA spectrograph common optical path subsystems and are the focus of this manuscript. At this time INAOE has finished the construction of the collimator and camera optics and the windows. The prisms manufacturing is in progress. The remaining coatings will be carried out at CIO.

Ground-based and Airborne Instrumentation for Astronomy VI, edited by Christopher J. Evans, Luc Simard, Hideki Takami Proc. of SPIE Vol. 9908, 990886 · C 2016 SPIE · CCC code: 0277-786X/16/\$18 · doi: 10.1117/12.2232210 


\section{OPTICAL DESIGN AND TRANSMISSION REQUIREMENTS}

MEGARA optical system design consists of:

- a pseudo-slit, which has $119 \mathrm{~mm}$ of length, and is composed by an arrangement of optical fibers. It is curved on a sphere surface of a radii of curvature (ROC) of $1075 \mathrm{~mm}$;

- the collimator, which is composed by one single and two double lenses, its focal length is $484.4 \mathrm{~mm}$ (at $632.8 \mathrm{~nm}$ ) and its f-number is 3.03 . The optical elements of the collimator are presented in table 2 . The only aspheric that is used is the COLL-S1;

- 18 high performance VPH gratings, which main characteristics are shown in table 1;

- the camera, composed by two doublets and three singlets with a total focal length of $245.9 \mathrm{~mm}$ (average paraxial value) and f-number of 1.54 . The last lens is the cryostat window and the image field is $61.4 \mathrm{~mm} \times 61.4 \mathrm{~mm}$;

- and the $4 \mathrm{k}$ x $4 \mathrm{k}$ pixel EV CCD detector.

The shutter and the cut-order filters are placed in the collimator barrel. Detailed information of the design requirements and as-built characteristics of the spectrograph are available in other publications ${ }^{4,5,6,7}$.

Figure 1 shows the component distribution of MEGARA along with the materials and diameters of each lens.

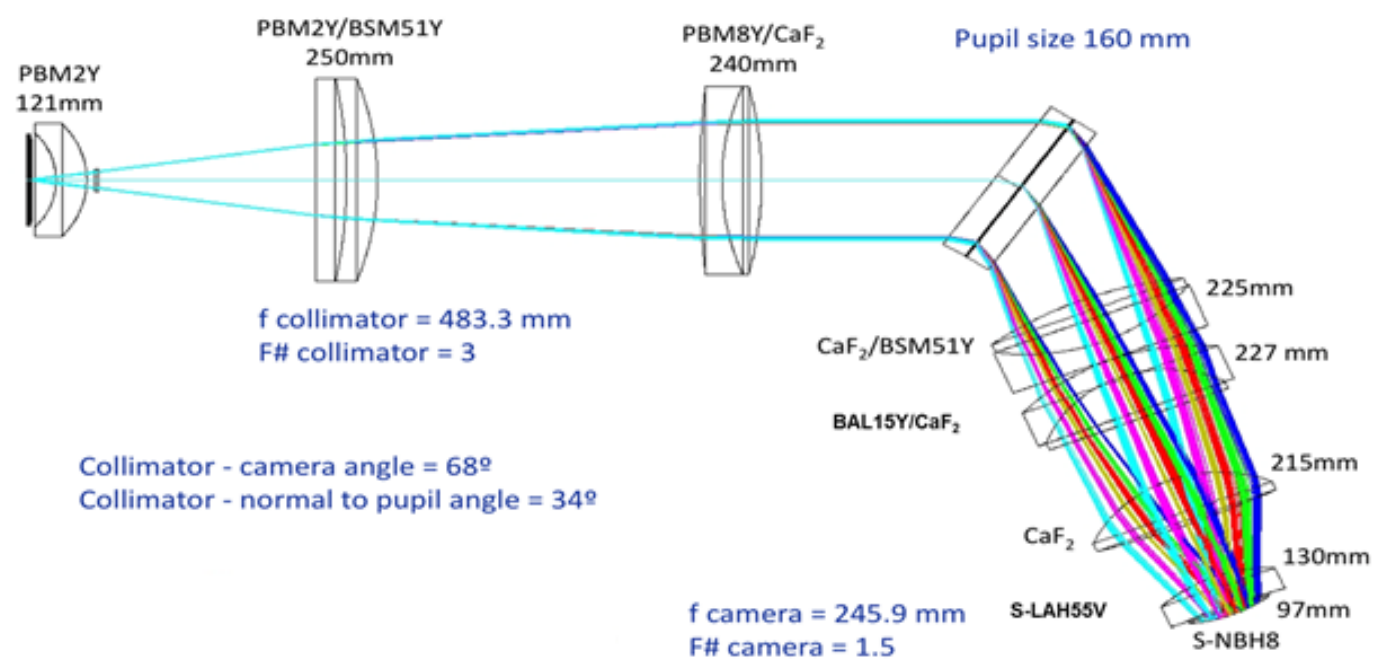

Figure 1. MEGARA optic system layout.

MEGARA offers resolutions of RFwHM $\sim 6,000,12,000$ and 18,700, respectively for the low-, mid- and high-resolution Volume Phase Holographic (VPH) gratings. The complete list of MEGARA gratings ${ }^{1}$ is given in table 1.

As a high-level requirement, it has been defined that the total MEGARA throughput, considering fiber link and spectrograph, should be better than $30 \%$ at the central wavelength of the VPH675-LR i.e. low-resolution grating working in the red; $\sim 670 \mathrm{~nm}$. This requirement is for the instrument only i.e. without including the GTC. 


\begin{tabular}{|c|c|c|c|c|c|c|c|}
\hline VPH NAME & SETUP & $\begin{array}{l}\mathbf{R}_{\text {FWHM }} \\
\end{array}$ & $\begin{array}{c}\lambda_{1}-\lambda_{2} \\
\AA\end{array}$ & $\begin{array}{l}\lambda \mathbf{c} \\
\AA \\
\AA\end{array}$ & $\begin{array}{c}\Delta \lambda(@ \lambda c) \\
\AA\end{array}$ & $\begin{array}{c}\begin{array}{c}\Delta \mathbf{v} \\
\mathrm{km} / \mathrm{s}\end{array} \\
\end{array}$ & $\begin{array}{c}\operatorname{lin} \text { res } \\
\AA / \text { pix }\end{array}$ \\
\hline "VPH405-LR & $\begin{array}{l}\text { LR-U } \\
\end{array}$ & 26028 & $23653-4386$ & 24051 & 0.672 & 250 & 0.17 \\
\hline VPH480-LR & LR-B & 6059 & $4332-5196$ & 4800 & 0.792 & 49 & 0.20 \\
\hline VPH570-LR & LR-V & 6080 & $5143-6164$ & 5695 & 0.937 & 49 & 0.23 \\
\hline VPH675-LR & LR-R & 6099 & $6094-7300$ & 6747 & 1.106 & 49 & 0.28 \\
\hline VPH799-LR & LR-I & 6110 & $7220-8646$ & 7991 & 1.308 & 49 & 0.33 \\
\hline VPH890-LR & LR-Z & 6117 & $8043-9630$ & 8900 & 1.455 & 49 & 0.36 \\
\hline VPH410-MR & MR-U & 12602 & $3917-4277$ & 4104 & 0.326 & 24 & 0.08 \\
\hline VPH443-MR & MR-UB & 12370 & $4225-4621$ & 4431 & 0.358 & 24 & 0.09 \\
\hline VPH481-MR & MR-B & 12178 & $4586-5024$ & 4814 & 0.395 & 25 & 0.10 \\
\hline VPH521-MR & MR-G & 12035 & $4963-5443$ & 5213 & 0.433 & 25 & 0.11 \\
\hline VPH567-MR & MR-V & 11916 & $5393-5919$ & 5667 & 0.476 & 25 & 0.11 \\
\hline VPH617-MR & MR-VR & 11825 & $5869-6447$ & 6170 & 0.522 & 25 & 0.13 \\
\hline VPH656-MR & MR-R & 11768 & $6241-6859$ & 6563 & 0.558 & 25 & 0.14 \\
\hline VPH712-MR & MR-RI & 11707 & $6764-7437$ & 7115 & 0.608 & 26 & 0.15 \\
\hline VPH777-MR & MR-I & 11654 & $7382-8120$ & 7767 & 0.666 & 26 & 0.17 \\
\hline VPH926-MR & MR-Z & 11638 & $8800-9686$ & 9262 & 0.796 & 26 & 0.20 \\
\hline VPH665-HR & HR-R & 18700 & $6445-6837$ & 6646 & 0.355 & 16 & 0.09 \\
\hline VPH863-HR & HR-I & 18701 & $8372-8882$ & 8634 & 0.462 & 16 & 0.12 \\
\hline
\end{tabular}

Table 1. MEGARA Baseline gratings. 18 configurations for several spectral ranges.

Table 2 summarizes the throughput expectations for the spectrograph common optical path only. This estimation includes the following contributors:

- Main Optics, which is composed by the collimator and the camera. We have assumed $1.5 \%$ Fresnel losses per glass/air interfaces and this implies that this is a worse case. INAOE and CIO provided coatings better than $1.3 \%$.

- Detector includes the Quantum efficiency of the CCD231-E74 (Astro multi-2 AR coating) as provided by e2V.

The column Spectrograph main optical path summarizes the spectrograph transmission taken into account the previous two contributors.

MEGARA main optics require broadband AR coatings in the wavelength range from 370 to $980 \mathrm{~nm}$ with $\mathrm{R}<1.3 \%$. The AR coatings have been optimized for a different mean AOI for each surface. Table 3 gives an overview of the whole system and the requirements for each main optics element.

MEGARA pupil elements wavelength range transmission is defined by the different spectral configurations: six for LR, ten for MR and two for HR. The specification for these elements is $\mathrm{R}<0.3 \%$ for the mean AOI that is different for each subgroup (LR, MR and HR). Table 4 provides a summary of all the pupil elements to be coated and their specific $\mathrm{AOI}$ and spectral ranges. 
MEGARA spectrograph main optical path

\begin{tabular}{|c|c|c|c|}
\hline$\lambda(\mathbf{n m})$ & Main Optics & Detector & $\begin{array}{l}\text { Main optical } \\
\text { path }\end{array}$ \\
\hline 365 & 0.126 & 0.650 & 0.082 \\
\hline 370 & 0.184 & 0.700 & 0.129 \\
\hline 380 & 0.317 & 0.800 & 0.254 \\
\hline 390 & 0.430 & 0.850 & 0.366 \\
\hline 405 & 0.534 & 0.910 & 0.486 \\
\hline 410 & 0.556 & 0.920 & 0.512 \\
\hline 440 & 0.637 & 0.910 & 0.580 \\
\hline 480 & 0.695 & 0.900 & 0.626 \\
\hline 500 & 0.721 & 0.890 & 0.642 \\
\hline 520 & 0.732 & 0.880 & 0.644 \\
\hline 550 & 0.749 & 0.890 & 0.667 \\
\hline 570 & 0.749 & 0.890 & 0.667 \\
\hline 600 & 0.749 & 0.900 & 0.674 \\
\hline 620 & 0.750 & 0.910 & 0.683 \\
\hline 665 & 0.751 & 0.920 & 0.691 \\
\hline 675 & 0.751 & 0.925 & 0.695 \\
\hline 700 & 0.752 & 0.930 & 0.699 \\
\hline 715 & 0.753 & 0.930 & 0.700 \\
\hline 750 & 0.755 & 0.930 & 0.702 \\
\hline 775 & 0.755 & 0.900 & 0.680 \\
\hline 800 & 0.755 & 0.880 & 0.664 \\
\hline 825 & 0.755 & 0.850 & 0.642 \\
\hline 850 & 0.755 & 0.800 & 0.604 \\
\hline 865 & 0.754 & 0.720 & 0.543 \\
\hline 900 & 0.750 & 0.600 & 0.450 \\
\hline 925 & 0.747 & 0.575 & 0.430 \\
\hline 940 & 0.746 & 0.400 & 0.298 \\
\hline 980 & 0.742 & 0.200 & 0.148 \\
\hline
\end{tabular}

Table 2. MEGARA Spectrograph main optical path throughput budget. We include the contributions from main optics and detector. 


\section{Main Optics AR Coatings}

\begin{tabular}{|c|c|c|c|c|c|c|c|c|}
\hline Element & Substrate & $\begin{array}{l}\text { Left surface } \\
\text { (S1) }\end{array}$ & $\begin{array}{l}\text { Mean } \\
\text { AOI } \\
\text { (deg) }\end{array}$ & R (\%) & $\begin{array}{l}\text { Right Surface } \\
\text { (S2) }\end{array}$ & $\begin{array}{c}\text { Mean } \\
\text { AOI } \\
\text { (deg) }\end{array}$ & R (\%) & $\begin{array}{c}\text { \# of } \\
\text { designs }\end{array}$ \\
\hline \multirow[t]{3}{*}{ Field Lens } & $\begin{array}{l}\text { Fused } \\
\text { Silica }\end{array}$ & \multirow{7}{*}{$\begin{array}{c}\text { Wide AR } \\
\text { coating 370- } \\
\mathbf{9 8 0 ~} \mathbf{~ n m}\end{array}$} & \multirow[t]{3}{*}{2} & \multirow[t]{7}{*}{$\mathrm{R}<1.3 \%$} & \multirow[t]{5}{*}{$\begin{array}{l}\text { Wide AR coating } \\
\mathbf{3 7 0 - 9 8 0} \mathbf{~ n m}\end{array}$} & \multirow[t]{3}{*}{2.8} & \multirow[t]{5}{*}{$\mathrm{R}<1.3 \%$} & \multirow[t]{3}{*}{2} \\
\hline & (SK1300) & & & & & & & \\
\hline & $\mathrm{ne}=1.46058$ & & & & & & & \\
\hline \multirow[t]{2}{*}{ COLL-S1 } & PBM2Y & & \multirow[t]{2}{*}{21.2} & & & \multirow[t]{2}{*}{17.1} & & \multirow[t]{2}{*}{2} \\
\hline & $\mathrm{nd}=1.62004$ & & & & & & & \\
\hline \multirow[t]{2}{*}{ COLL-D2 } & PBM2Y & & \multirow[t]{2}{*}{4.9} & & \multirow{2}{*}{\multicolumn{3}{|c|}{ No coating }} & \multirow[t]{2}{*}{1} \\
\hline & $\mathrm{nd}=1.62004$ & & & & & & & \\
\hline \multirow[t]{2}{*}{ COLL-D3 } & BSM51Y & \multirow{2}{*}{\multicolumn{3}{|c|}{ No coating }} & \multirow{2}{*}{$\begin{array}{l}\text { Wide AR coating } \\
\mathbf{3 7 0 - 9 8 0 ~} \mathbf{~ m m}\end{array}$} & \multirow[t]{2}{*}{8.5} & \multirow[t]{2}{*}{$\mathrm{R}<1.3 \%$} & \multirow[t]{2}{*}{1} \\
\hline & $\mathrm{nd}=1.60311$ & & & & & & & \\
\hline \multirow[t]{2}{*}{ COLL-D4 } & PBM8Y & \multirow{2}{*}{$\begin{array}{l}\text { Wide AR } \\
\text { coating } 370- \\
\mathbf{9 8 0} \mathbf{~} \mathbf{m}\end{array}$} & \multirow[t]{2}{*}{4.5} & \multirow[t]{2}{*}{$\mathrm{R}<1.3 \%$} & \multirow{2}{*}{\multicolumn{3}{|c|}{ No coating }} & 1 \\
\hline & $\mathrm{nd}=1.59551$ & & & & & & & \\
\hline \multirow[t]{2}{*}{ COLL-D5 } & CaF2 & \multirow{2}{*}{\multicolumn{3}{|c|}{ No coating }} & Wide AR coating & 7.3 & $\mathrm{R}<1.3 \%$ & 1 \\
\hline & $\mathrm{nd}=1.43384$ & & & & $3 / 0-980 \mathrm{~nm}$ & & & \\
\hline \multirow[t]{2}{*}{ CAM-D1 } & CaF2 & \multirow{2}{*}{$\begin{array}{l}\text { Wide AR } \\
\text { coating } \mathbf{3 7 0}- \\
\mathbf{9 8 0} \mathbf{~ n m}\end{array}$} & 10.8 & $\mathrm{R}<1.3 \%$ & No & ating & & 1 \\
\hline & $\mathrm{nd}=1.43384$ & & & & & & & \\
\hline CAM-D2 & BSM51Y & & coatin & & Wide AR coating & 5.8 & $\mathrm{R}<1.3 \%$ & 1 \\
\hline & $\mathrm{nd}=1.60311$ & & & & $370-980$ nm & & & \\
\hline CAM-D3 & BAL15Y & Wide AR & 13 & $\mathrm{R}<1.3 \%$ & No & ating & & 1 \\
\hline & $\mathrm{nd}=1.55671$ & $980 \mathrm{~nm}$ & & & & & & \\
\hline CAM-D4 & CaF2 & & coatin & & Wide AR coating & 5.6 & $\mathrm{R}<1.3 \%$ & 1 \\
\hline & $\mathrm{nd}=1.43384$ & & & & $370-980$ nm & & & \\
\hline CAM-S5 & CaF2 & Wide AR & 18.5 & $\mathrm{R}<1.3 \%$ & & 12 & & 2 \\
\hline & $\mathrm{nd}=1.43384$ & $980 \mathrm{~nm}$ & & & & & & \\
\hline CAM-S6 & S-LAH55V & & 9.3 & & & 11.7 & & 2 \\
\hline & $\mathrm{nd}=1.83481$ & & & & & & & \\
\hline CAM-S7 & S-NBH8 & & 20.3 & & & 14.8 & & 2 \\
\hline & $\mathrm{nd}=1.72047$ & & & & & & & \\
\hline
\end{tabular}

Table 3. Summary of the main optics AR coatings designed for MEGARA. 


\section{Windows and Prisms AR Coatings}

\begin{tabular}{|c|c|c|c|c|}
\hline Element & Substrate & Surface AR Width & Mean AOI (deg) & $\mathbf{R}(\%)$ \\
\hline $\begin{array}{c}(\mathrm{LR}-\mathrm{U}) \\
\text { windows (2) }\end{array}$ & \multirow{6}{*}{$\begin{array}{c}\text { Fused Silica } \\
(\mathrm{SK} 1300) \\
\mathrm{ne}=1.46058\end{array}$} & $360 \mathrm{~nm}-445 \mathrm{~nm}$ & \multirow[t]{6}{*}{34} & \multirow[t]{18}{*}{$\mathrm{R}<0.3 \%$} \\
\hline $\begin{array}{c}\text { (LR-B) } \\
\text { windows (2) }\end{array}$ & & $390 \mathrm{~nm}-570 \mathrm{~nm}$ & & \\
\hline $\begin{array}{c}(\mathrm{LR}-\mathrm{V}) \\
\text { windows (2) }\end{array}$ & & $470 \mathrm{~nm}-620 \mathrm{~nm}$ & & \\
\hline $\begin{array}{c}(\mathrm{LR}-\mathrm{R}) \\
\text { windows (2) }\end{array}$ & & $550 \mathrm{~nm}-780 \mathrm{~nm}$ & & \\
\hline $\begin{array}{c}(\mathrm{LR}-\mathrm{I}) \\
\text { windows (2) }\end{array}$ & & $670 \mathrm{~nm}-920 \mathrm{~nm}$ & & \\
\hline $\begin{array}{c}(\mathrm{LR}-\mathrm{Z}) \\
\text { windows (2) }\end{array}$ & & $750 \mathrm{~nm}-990 \mathrm{~nm}$ & & \\
\hline $\begin{array}{c}(\mathrm{MR}-\mathrm{U}) \\
\text { prisms (2) }\end{array}$ & \multirow{12}{*}{$\begin{array}{c}\text { PMB2Y } \\
\mathrm{nd}=1.62004\end{array}$} & $380 \mathrm{~nm}-440 \mathrm{~nm}$ & \multirow[t]{10}{*}{10.5} & \\
\hline $\begin{array}{l}\text { (MR-UB) } \\
\text { prisms (2) }\end{array}$ & & $410 \mathrm{~nm}-480 \mathrm{~nm}$ & & \\
\hline $\begin{array}{c}\text { (MR-B) } \\
\text { prisms (2) }\end{array}$ & & $440 \mathrm{~nm}-520 \mathrm{~nm}$ & & \\
\hline $\begin{array}{l}\text { (MR-G) } \\
\text { prisms (2) }\end{array}$ & & $480 \mathrm{~nm}-560 \mathrm{~nm}$ & & \\
\hline $\begin{array}{l}(\mathrm{MR}-\mathrm{V}) \\
\text { prisms (2) }\end{array}$ & & $520 \mathrm{~nm}-610 \mathrm{~nm}$ & & \\
\hline $\begin{array}{l}\text { (MR-VR) } \\
\text { prisms (2) }\end{array}$ & & $570 \mathrm{~nm}-660 \mathrm{~nm}$ & & \\
\hline $\begin{array}{l}\text { (MR-R) } \\
\text { prisms (2) }\end{array}$ & & $610 \mathrm{~nm}-700 \mathrm{~nm}$ & & \\
\hline $\begin{array}{l}\text { (MR-RI) } \\
\text { prisms (2) }\end{array}$ & & $660 \mathrm{~nm}-760 \mathrm{~nm}$ & & \\
\hline $\begin{array}{c}\text { (MR-I) } \\
\text { prisms (2) }\end{array}$ & & $720 \mathrm{~nm}-830 \mathrm{~nm}$ & & \\
\hline $\begin{array}{l}\text { (MR-Z) } \\
\text { prism (2) }\end{array}$ & & $860 \mathrm{~nm}-980 \mathrm{~nm}$ & & \\
\hline $\begin{array}{c}(\mathrm{HR}-\mathrm{R}) \\
\text { prisms (2) }\end{array}$ & & $630 \mathrm{~nm}-700 \mathrm{~nm}$ & 34 & \\
\hline $\begin{array}{c}\text { (HR-I) } \\
\text { prisms (2) }\end{array}$ & & $820 \mathrm{~nm}-900 \mathrm{~nm}$ & & \\
\hline
\end{tabular}

Table 4. Summary of the pupil elements AR coatings designed for MEGARA. 


\section{ANTIREFLECTIVE COATINGS DESIGN}

Antireflection coatings can range from a simple single layer having virtually zero reflectance at just one wavelength, to a multilayer system of more than a dozen layers, having virtually zero reflectance over a range of several octaves.

In the case of the main optics a wide spectral region needs to be covered, thus the apparent dispersion of the equivalent periods may cause trouble. This dispersion can be reduced by using equivalent periods of one-eighth-wave thickness instead of quarter-wave. Each quarter wave in the original design is then replaced by two periods in series. This adds considerably the number of layers. ${ }^{8}$

The MEGARA main optics AR designed coatings consist in eight layers of three different materials to fulfill the requirements of transmission in the wavelength range at the AOI presented in table 3.

The range of the AR for the pupil elements is considerably narrower compared to that of the main optics, thus the requirements are more demanding, to fulfill these, several four layer designs were produced and optimized for each spectral band presented in table 4 .

Theoretical designs were achieved through different methods ${ }^{9,}{ }^{10}$ based on the materials available for the deposition. Then an optimization of the design is implemented defining the targets of reflection and the mean AOI of each optical element.

A Damped Least-Square algorithm was used for optimization with iterations variating from 100 to 200 . Specialized software was used and due to the wide range of wavelengths in the main optics, dispersion of the materials to be deposited in the substrate was acknowledged.

A total of 18 designs were developed for the main optics and another 18 for the pupil elements including LR windows and MR - HR prisms.

\section{ANTIREFLECTIVE COATINGS TESTING RESULTS}

After the fabrication of each of the optical elements, the deposition of the coating materials was made in the Integrity 39 Denton Vacuum Deposition System located at CIO, León, Guanajuato and the transmission of the coating on a witness was measured in an Agilent Cary-5000-UV-Vis-NIR ${ }^{\circledR}$ spectrophotometer.

Several witness samples of each substrate were polished and coated to make the transmission measurements prior and during the final deposition. Three transmission measurements were carried for each one and the average was computed. To extract the transmission of the coated surface of the witness from the measurement, the procedure was the following:

1. A simulation of the substrates was made, in Zemax, emulating a witness with an ideally perfect AR where the transmission is $99.99 \%$.

2. Theoretical values of the total transmission are obtained. .

3. Fresnel losses on the uncoated surface of the sample and absorption losses of the substrate from the measurement were eliminated dividing by the theoretical transmission of the witness sample.

In cases when the $\mathrm{AOI} \geq 10^{\circ}$ the measurement could not be taken directly at the angle specified. To sort out this limitation, the measurements of transmission of the witnesses were taken at normal incidence and then extrapolated to the designated AOI of each element using the method described below:

i. Theoretical transmission functions of the coating at normal incidence and at the mean AOI were produced aided by optical software.

ii. A coefficient function was achieved by dividing the transmission function at the mean AOI by that at normal incidence.

iii. The transmission of the witness sample was measured at normal incidence using the Cary-5000 spectrophotometer at CIO.

iv. The witness sample transmission at the mean AOI was inferred from the experimental data measured at normal incidence, applying the coefficients obtained in (ii).

v. The effects of absorption and the reflections in the uncoated side of the sample were eliminated using the method described above, steps 1-3.

In the following figures we present the performance results of the current coated elements of the main optics. 


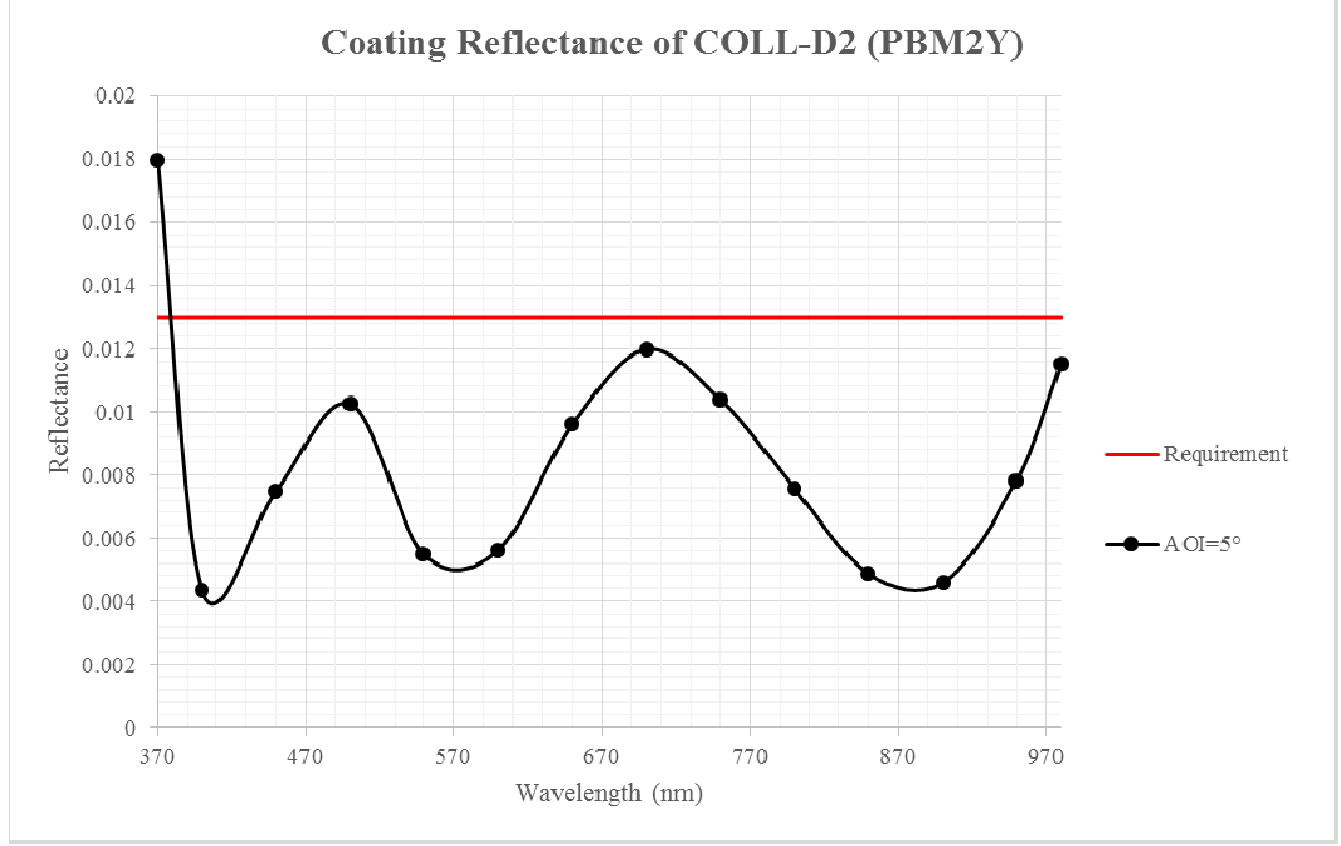

Figure 2. Performance of the AR coating in PBM2Y substrate at incidence of $5^{\circ}$.

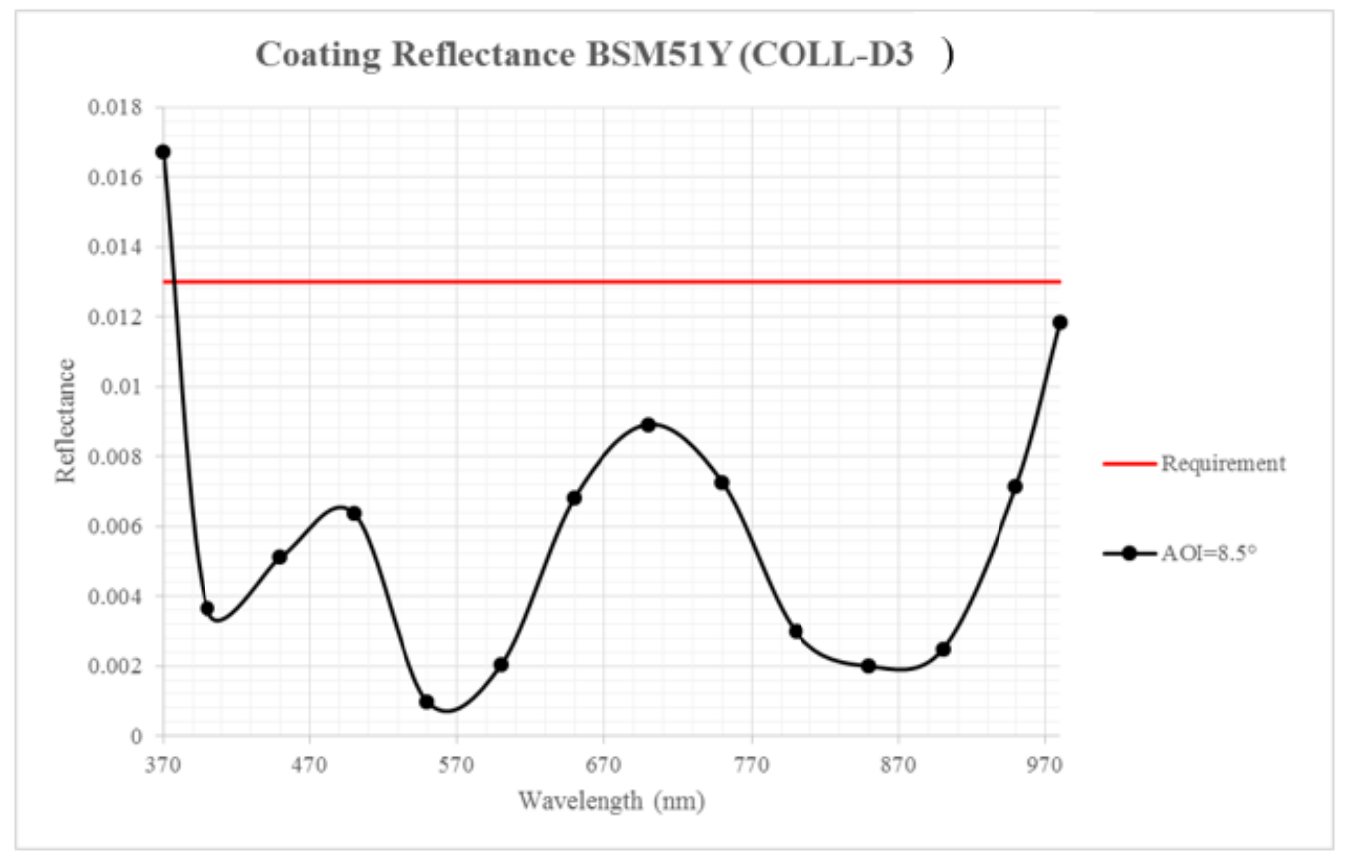

Figure 3. Performance of the AR coating in BSM51Y substrate at incidence of $9^{\circ}$. 


\section{Coating Reflectance PBM8Y (COLL-D4)}

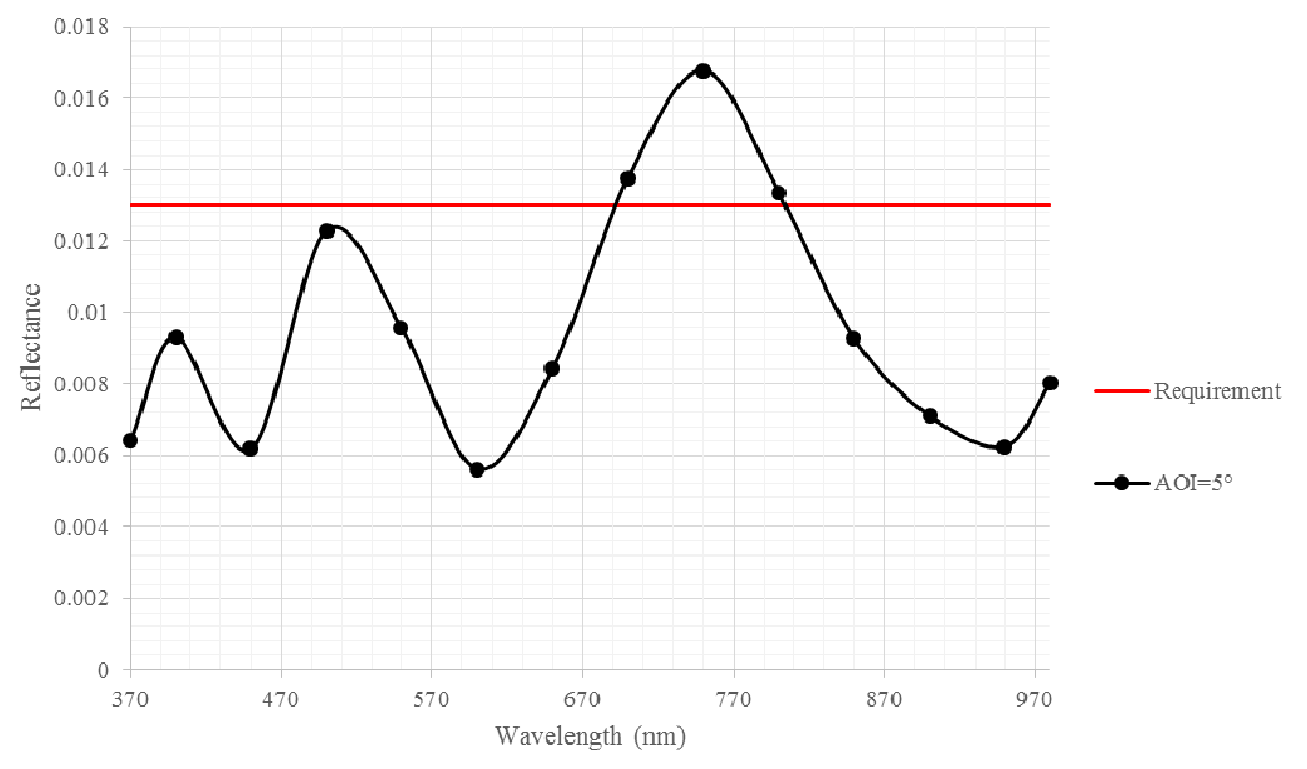

Figure 4. Performance of the AR coating in PBM8Y substrate at incidence of $5^{\circ}$.

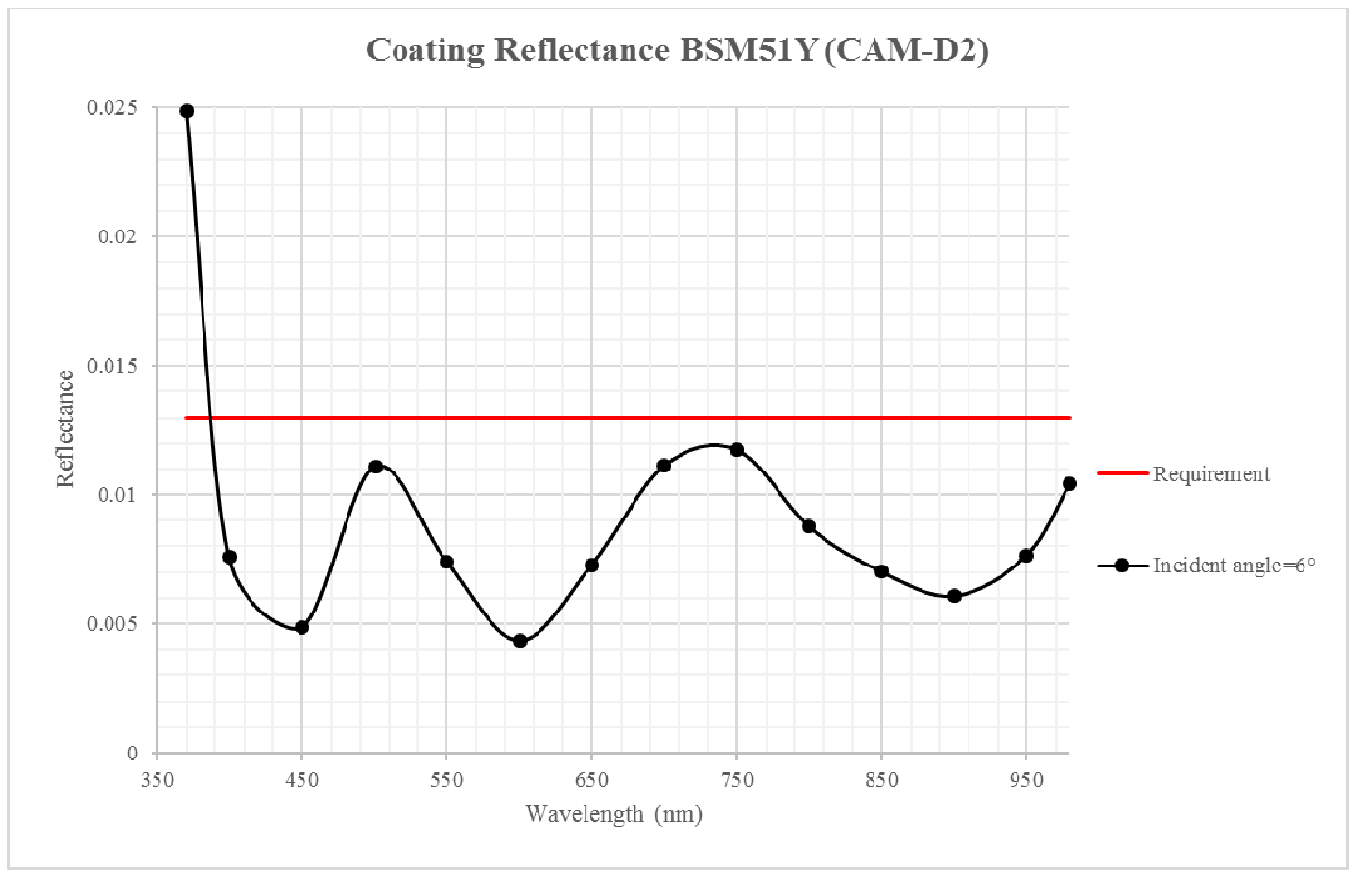

Figure 5. Performance of the AR coating in BSM51Y substrate at incidence of $6^{\circ}$.

Proc. of SPIE Vol. $9908990886-9$ 


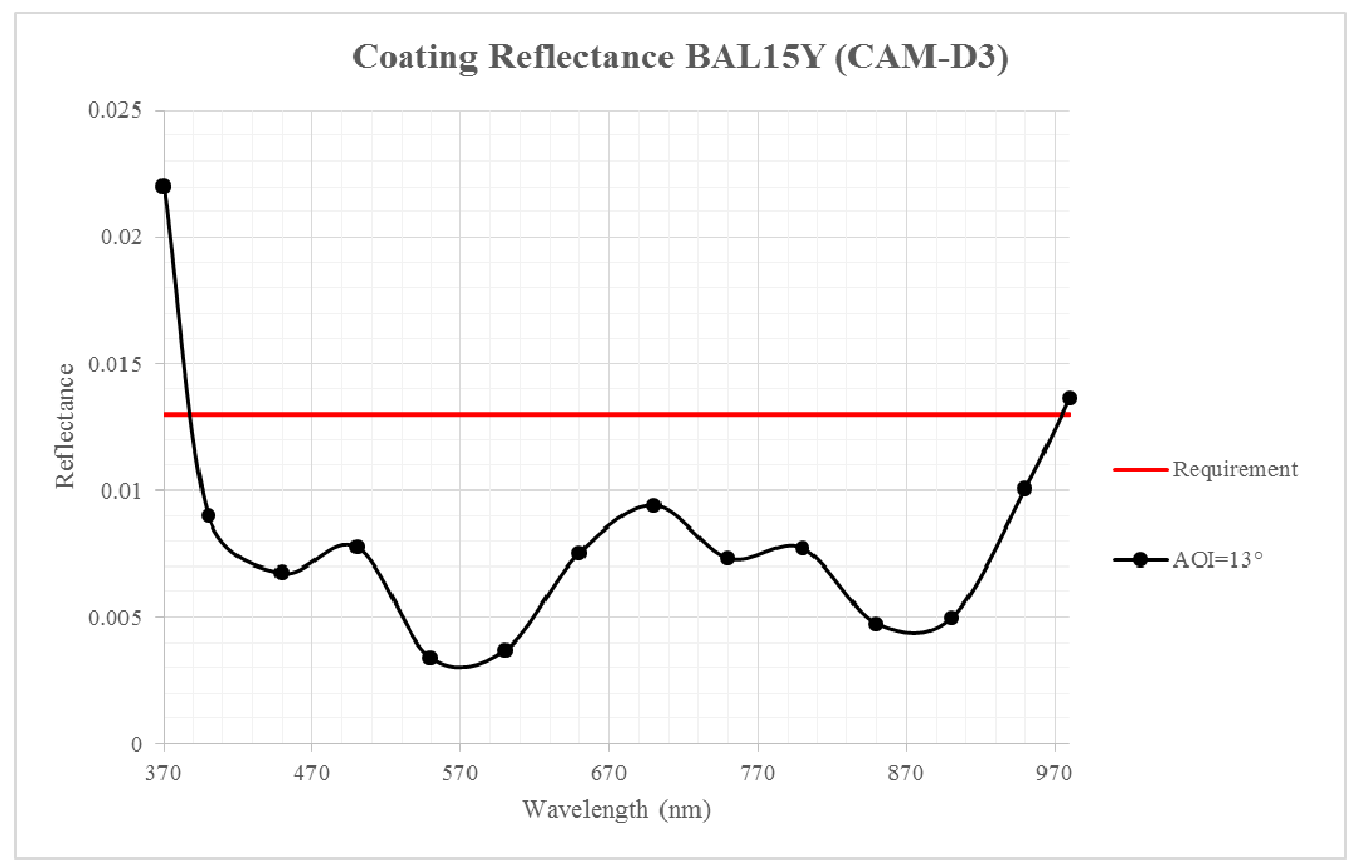

Figure 6. Performance of the AR coating in BAL15Y substrate at incidence of $13^{\circ}$.

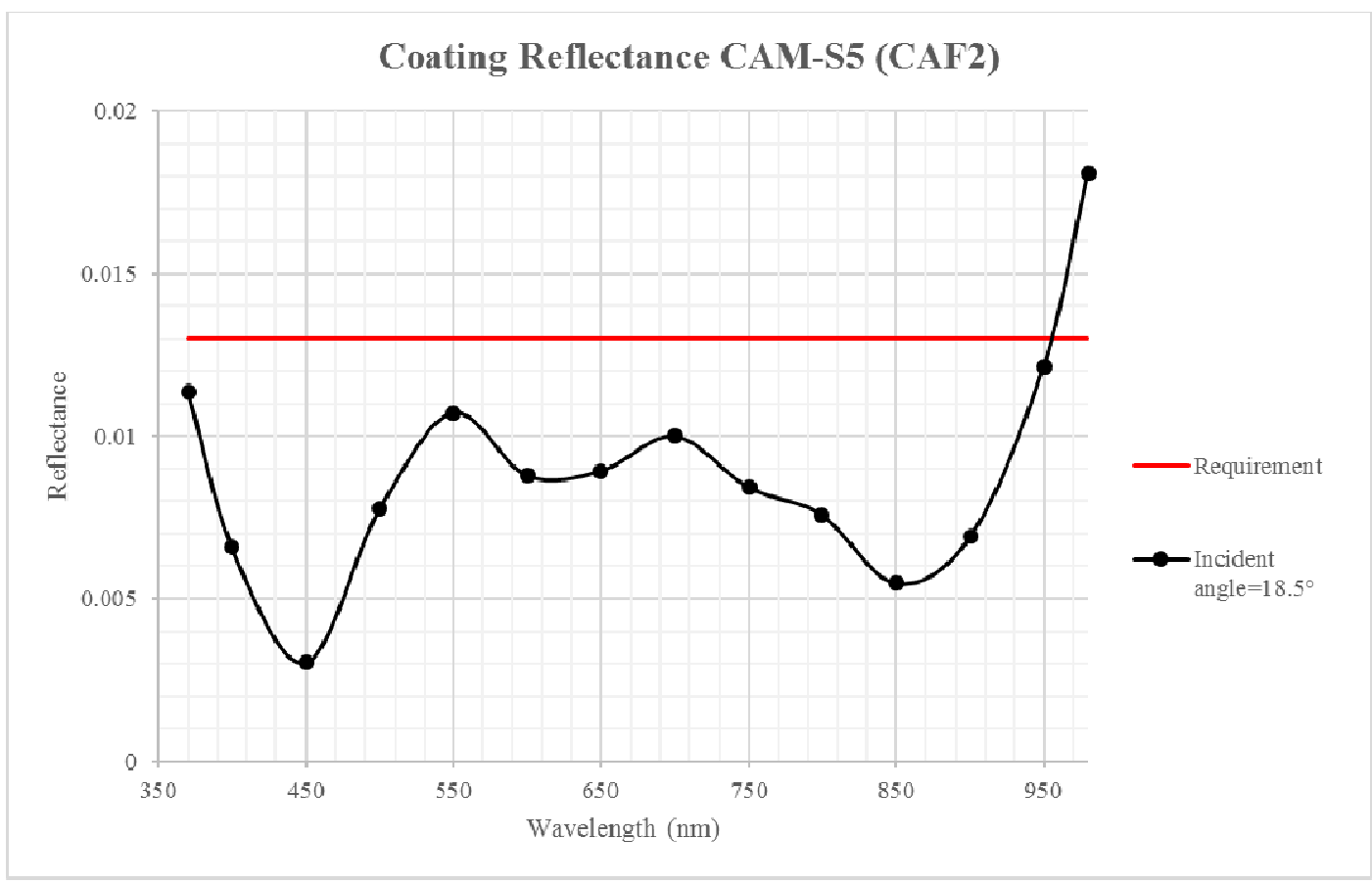

Figure 7. Performance of the AR coating in CAF2 substrate at incidence of $18.5^{\circ}$.

Proc. of SPIE Vol. 9908 990886-10 


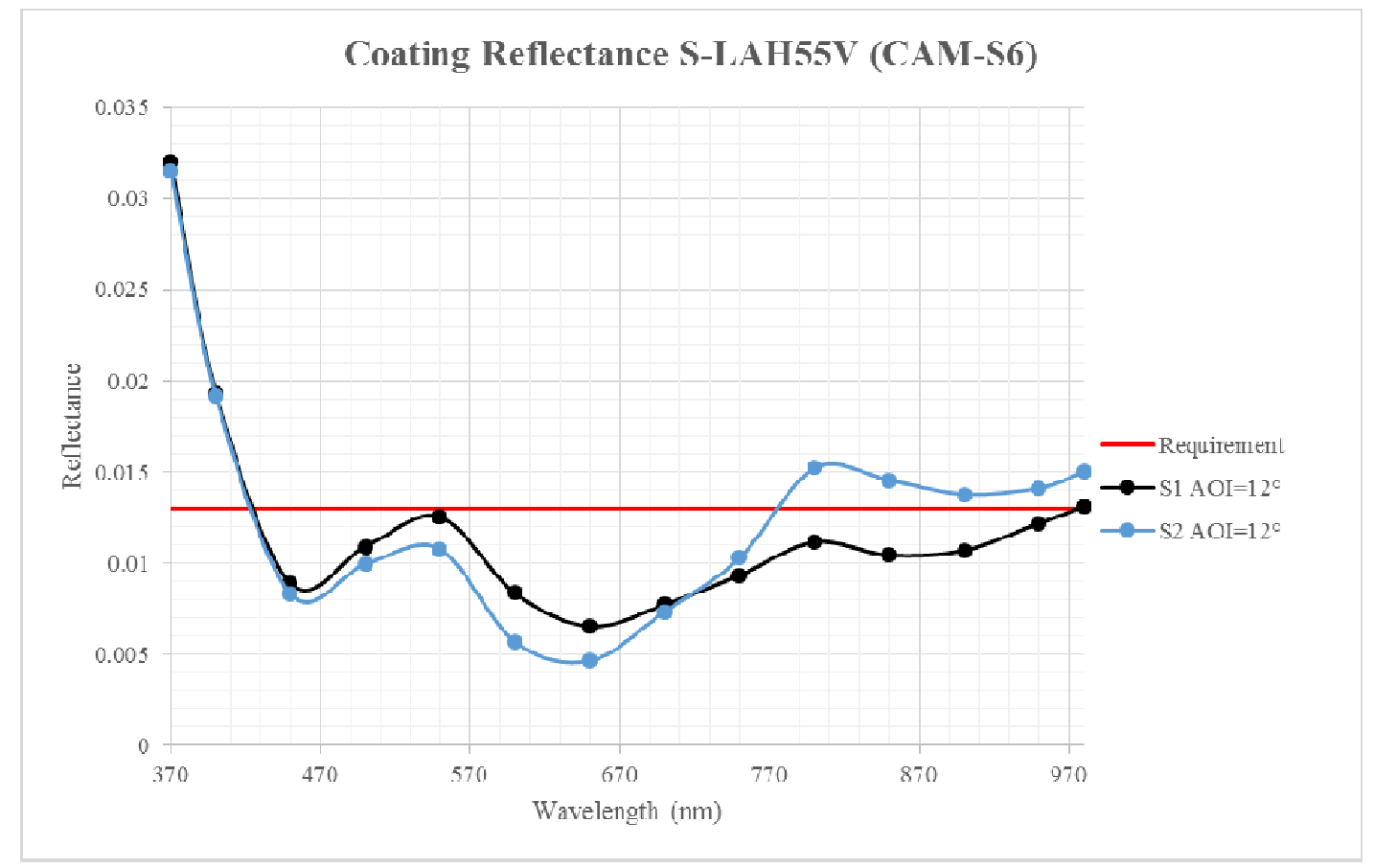

Figure 8. Performance of the AR coating in S-LAH55V substrate at incidence of $12^{\circ}$. Both surfaces of CAM-S6 are presented.

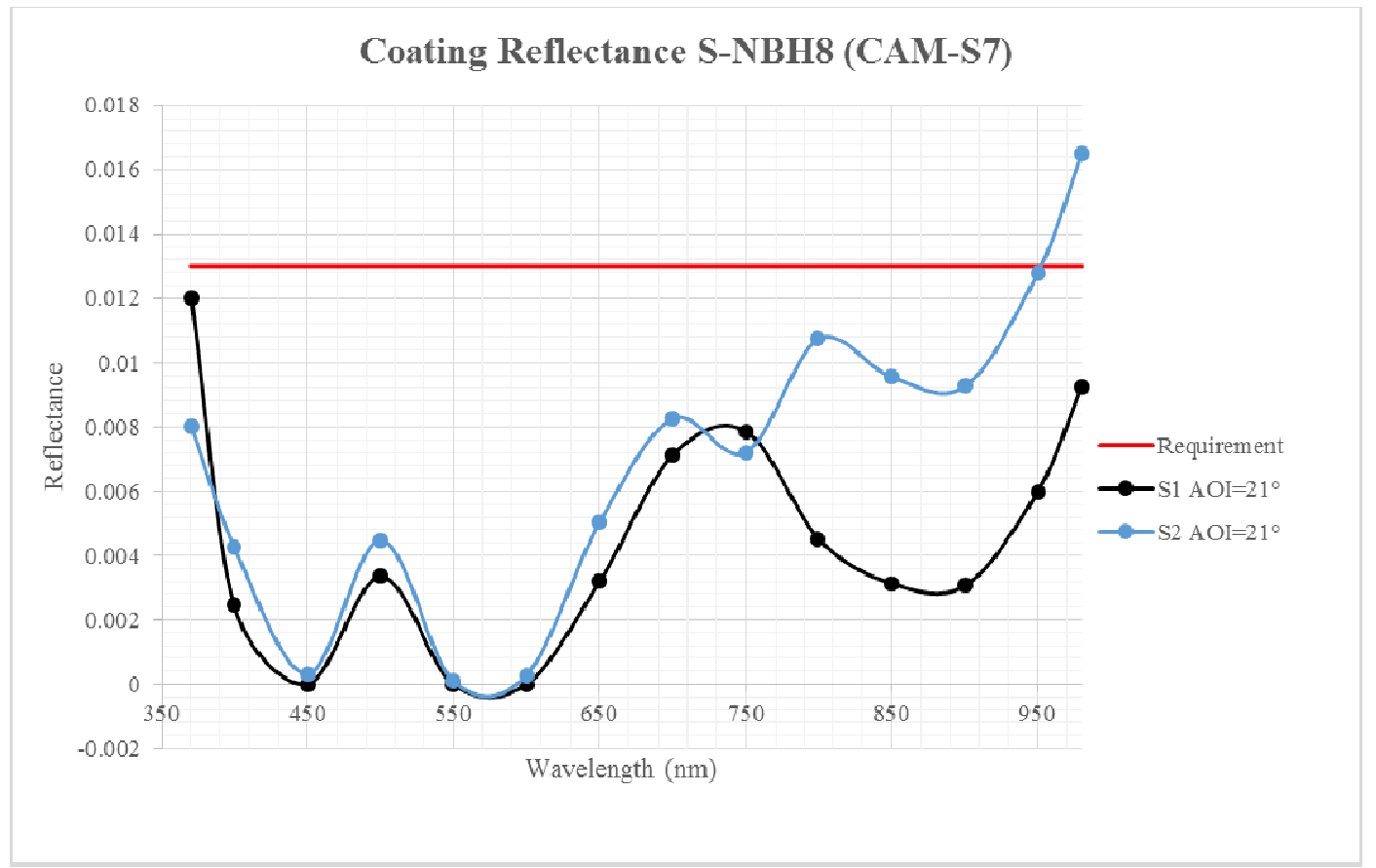

Figure 9. Performance of the AR coating in S-NBH8 substrate at incidence of $21^{\circ}$. Both surfaces of CAM-S7 are presented. 


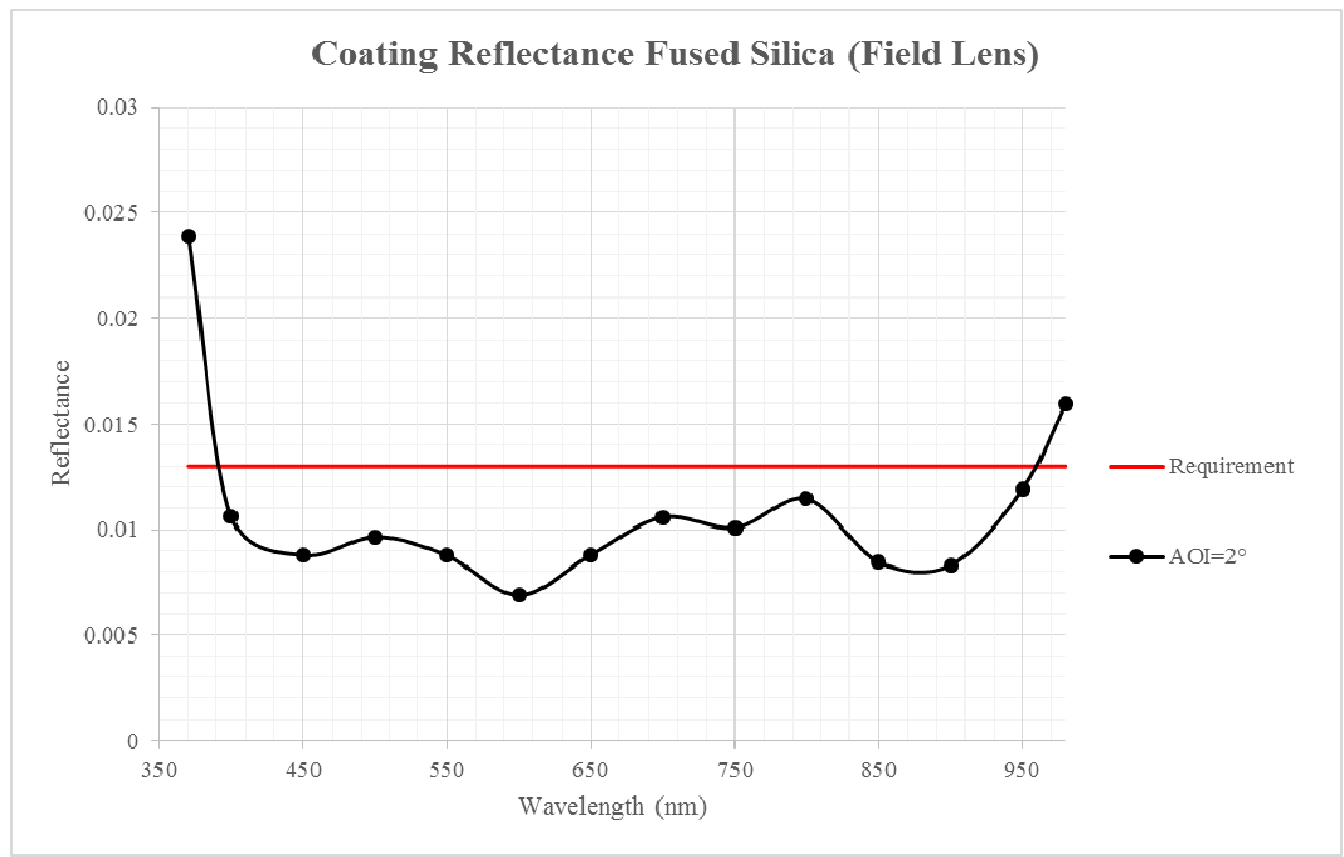

Figure 10. Performance of the AR coating in Fused Silica substrate at incidence of $2^{\circ}$.

\begin{tabular}{l}
\hline \hline \multicolumn{2}{l}{ Coated Element } \\
\begin{tabular}{|l|l||}
\hline Field Lens & 0.011 \\
\hline COLL-S1 S1* & 0.013 \\
\hline COLL-S1 S2* & 0.013 \\
\hline COLL-D2 & 0.009 \\
\hline COLL-D3 & 0.006 \\
\hline COLL-D4 & 0.009 \\
\hline CAM-D2 & 0.009 \\
\hline CAM-D3 & 0.008 \\
\hline CAM-S5 S1 & 0.009 \\
\hline CAM-S5 S2 & 0.009 \\
\hline CAM-S6 S1 & 0.012 \\
\hline CAM-S6 S2 & 0.013 \\
\hline CAM-S7 S1 & 0.004 \\
\hline CAM S7 S2 & 0.007 \\
\hline AVERAGE TOTAL LOSS & 0.124 \\
\hline
\end{tabular}
\end{tabular}

Table 5. Average reflectance of main optics coated elements including the total loss due to the main optics. *Estimated values.

Proc. of SPIE Vol. 9908 990886-12 
All AR coatings of the main optics fulfill the requirement of average reflectance $\leq .0 .013$ maintaining stability throughout the spectral range as can be seen in table 5 and figures 2 to 10 . The total average loss of the main optics is estimated in 0.124 this gives a total average throughput of 0.876 . Compared to the average values in table 2 where the average total throughput is 0.659 there is an improvement of $33 \%$.

Currently the pupil elements are being coated, the windows for LR configurations are already finished and their average reflectance is shown in table 5. It can be noticed that the requirement of average reflectance $\leq .0 .003$ is not completely fulfilled. Such small values of reflectance are more complicated to measure and several times they are within the error of the measurement instrument. Thus, the decision was made to go on with these depositions as they do not affect substantially the overall performance of the spectrograph.

\begin{tabular}{|c|c|}
\hline \hline $\begin{array}{c}\text { Coated } \\
\text { Element }\end{array}$ & $\begin{array}{c}\text { Average } \\
\text { Reflectance }\end{array}$ \\
\hline LR-U & 0.005 \\
\hline LR-B & 0.009 \\
\hline LR-V & 0.004 \\
\hline LR-R & 0.004 \\
\hline LR-Z & 0.003 \\
\hline
\end{tabular}

Table 6. Average reflectance of LR coated windows.

\section{CONCLUSIONS AND FURTHER WORK}

Currently all the main optic elements from the collimator and the camera have been built, coated and delivered to UCM., The LR windows are already coated and delivered. The HR windows have been delivered. Thirty out thirty six MR windows have been finished and delivered. The MR prisms manufacturing is in progress, AR coating designs have been developed and are now being tested.

The broad band AR designs of the main optics have been effectively tested using a method of analysis to remove Fresnel effects. Transmission data obtained at normal incidence were extrapolated to other AOIs. In most of the spectral bands the AR coatings exceed the performance requirements.

We present the global average transmission of the spectrograph and compared with the expected one. The spectrograph global transmission is better by $33 \%$ than the requirement. Therefore, MEGARA spectrograph throughput will be the best in a $10 \mathrm{~m}$ telescope. 


\section{REFERENCES}

[1] Gil de Paz, A., et al., "MEGARA: the future optical IFU and multi-object spectrograph for the 10.4m GTC telescope", Proc. of SPIE Vol. 8446, 84464Q-1-9 (2012)

[2] Gil de Paz, A., et al., "MEGARA: a new generation optical spectrograph for GTC", Proc. of SPIE Vol. 9147, 23 (2014)

[3] Gil de Paz, A., et al., "MEGARA, the new intermediate-resolution optical IFU and MOS for GTC: getting ready for the telescope", Proc. of SPIE, this volume (2016)

[4] Carrasco, E., et al., "Performance of MEGARA spectrograph optical elements", Proc. of SPIE, this volume (2016)

[5] Carrasco, E., et al., "MEGARA spectrograph optics", Proc. of SPIE, Vol. 8011, 80112D (2012)

[6] Sánchez-Blanco, E., García-Vargas, M. L., Ortiz, R., "MEGARA Detailed Design: Spectrograph Optics", TEC/MEG/100, MEGARA consortium internal technical report, 1-59 (2014)

[7] Ortiz, R., et al., "Inverse analysis method to optimize the optic tolerances of MEGARA: the future IFU and MultiObject Spectrograph for GTC", Proc. of SPIE, Vol. 9147, id. 914749 (2014)

[8] Macleod, H. A., [Thin-Film Optical Filters], CRC Press, Florida, 4th Edition (2010).

[9] Schallenberg, U., "Design principles for broadband AR coatings", Proceedings of the Society of Photo-Optical Instrumentation Engineers 7101 710103-1-710103-8 (2008)

[10] Schallenberg U., “Antireflection design concepts with equivalent layers” Appl Opt 45 1507-1514 (2006) 